\title{
Serviço social e sistema de bem-estar: semelhanças e diferenças entre Portugal, Espanha e Alemanha
}

\author{
Social work and welfare system: \\ Commonalities and differences between Portugal, Spain and Germany
}

\section{Maria Irene Carvalho *}

\begin{abstract}
Resumo:
O desenvolvimento do Estado Providência cruza-se com o conhecimento e acção do Serviço Social. Especialistas nesta área defendem que o conhecimento e a acção do Serviço Social estão associados ao tipo de Estado Providência prosseguido em cada país. Neste âmbito, consideramos a relação entre o Serviço Social e o sistema de bem-estar em três países europeus Portugal, a Espanha e a Alemanha numa perspectiva comparada demonstrando as suas semelhanças e diferenças.
\end{abstract}

Palavras-chave: Serviço social. Estado Providência. Semelhanças. Diferenças.

\begin{abstract}
:
The development of the welfare state intersects with the knowledge and the Social Action. Specialists in this area argue that knowledge and action are associated with Social Service to the type of welfare state pursued in each country. In this context, we consider the relationship between social work and welfare system in three European countries Portugal, Spain and Germany in comparative perspective, showing their commonalities and differences.
\end{abstract}

Keywords: Social work. Welfare. Commonalities. Differences.

\section{Introdução}

Este texto resulta de uma pesquisa realizada no âmbito de uma formação especializada em Serviço Social numa perspectiva europeia. Pretende-se reflectir sobre Serviço Social e o sistema de bem-estar em diferentes países europeus a partir de uma análise comparada tendo em conta as diferenças e semelhanças entre o conhecimento do

\footnotetext{
* Universidade Lusófona de Lisboa. Doutorada em Serviço Social, docente universitária, investigadora. mariacarvalho21@hotmail.com
} 
serviço social e o sistema de bem-estar social em países como Portugal, a Espanha e a Alemanha.

Esta análise baseia-se numa perspectiva teórica construtivista. A ideia de construção social do conhecimento significa que este rege o nosso comportamento, do qual todos temos opiniões diferentes (BERGER; LUCKMANN, 1987). Apesar dessa heterogeneidade é possível chegar a pontos de vista alguns objectivos comuns e socialmente aceites que podem ser alcançados através da institucionalização e legitimação de padrões de conhecimento comum, o que implica certas convenções pelas quais as pessoas se comportam na sociedade. Este processo não é estático, mas sim dinâmico e está associada a uma espiral de criação e recriação das estruturas e convenções sociais decorrentes da interacção social.

Este processo está associado ao sistema sócio-histórico de modernização das sociedades (FLORA; HEIDENHEIMER, 1995; MOZZICAFREDDO, 2000). Integra as dimensões económica, política mundial e da vida e pode implicar uma acção comunicativa. As mudanças sociais circulam em torno de dois sistemas fundamentais: o sistema de produção - trabalho - do qual derivam dois subsistemas - a economia e a política, e segundo o sistema - o mundo da vida - está associado ao subsistema da família e da sociedade civil (HABERMAS, 1987; VEENKAMP, 2006). Estes sistemas e subsistemas permitem analisar o modo como as sociedades interagem, modernizam, constroem e compreendem o modo como influenciam e determinam padrões aceitáveis de conhecimento e as acções de Serviço Social desenvolvidas nessas sociedades.

Neste sentido analítico, o Serviço Social é considerado como uma construção social (FOOK, 2003; PAYNE, 1995). Neste âmbito podem ser identificados alguns factores que determinam o seu conhecimento e actuação profissional tais como: o tipo de conhecimento científico e dominante e/ ou paradigmas teóricos alternativos, o tipo de desenvolvimento económico e intervenção do Estado no que diz respeito à forma objectiva e subjectiva dos direitos do cidadão, o modo como a política e o Serviço Social como profissão responde aos actuais e problemas sociais emergentes, o tipo de elites emergentes e grupos de pressão, bem como os princípios, valores e culturas.

O modo como esses factores interagem e se inter-relacionam ao processo sóciohistórico de desenvolvimento das sociedades, legítima e institucionaliza o 
desenvolvimento académico e prático da profissão, o seu campo de acção e seus modos operandi, bem como a sua autonomia e reconhecimento profissional. Assume igualmente o sistema de bem-estar como um produto da modernização da sociedade e como um processo de mobilização social e política do mundo da vida, que, juntos, têm tornado possível a universalização dos direitos cívicos e políticos e a organização de uma matriz institucional de regras das relações sociais e dos direitos sociais (COUSINS, 2005; FLORA; HEIDENHEIMER, 1995; MOZZICAFREDDO, 2000).

O Serviço Social ocupa uma posição de charneira entre os diferentes sistemas e subsistemas, entre o económico/ político (racional) e o mundo da vida (subjectivo). No entanto, o Serviço Social está explicitamente ligado ao subsistema de políticas de bemestar e ao mundo da vida e, implicitamente, ao subsistema económico, uma vez que muitas acções do Estado e do mundo da vida podem ou não produzir o bem-estar e também influencia a forma como o mercado produz riqueza e vice-versa. Esta questão é uma das equações fundamentais na implementação da coesão social europeia implícita nas estratégias de Lisboa e de Nice (COMISSÃO EUROPEIA, 2000; 2001), o que implica o desenvolvimento económico e tecnológico, formação, produção, mobilidade, aumento de riqueza e consequentemente, a criação de bem-estar de acordo com os padrões culturais de cada sociedade.

\section{Objectivos e metodologia da pesquisa}

Para a elaboração do texto definiram-se alguns objectivos e metodologias associadas. A partir de uma perspectiva sócio-histórica, económica e social, os principais objectivos da pesquisa são:

a) Compreender como o poder central e local coordena e administra recursos nas áreas da protecção social, relativamente às pensões e complementos e aos serviços sociais;

b) Analisar o Serviço Social em relação com os sistemas de protecção social - ou sistemas de segurança social - e identificação de áreas, organizações e problemas;

c) Reflectir sobre as orientações das políticas sociais e como as mesmas influenciam a acção social, bem como a sua situação profissional em cada país. 
Metodologicamente, este trabalho assume uma postura exploratória centrada principalmente sobre a metodologia qualitativa comparada, orientada por um processo de interpretação reflexiva (KANTOWICZ, 2005). Numa primeira fase, foram realizadas uma série de actividades de pesquisa bibliográfica e uma análise documental de textos pesquisados sobre o Serviço Social, metodologias e configurações do Estado. Em seguida, foi construída uma tabela de análise para as categorias previamente definidas, que integra a dimensão da evolução sócio-histórico e política do Serviço Social ao longo dos últimos trinta anos nas sociedades dos países estudados. Depois de elaborado o quadro, continuamos com o processo de recolha de dados no que diz respeito às dimensões estudadas em conjunto com colegas, profissionais e estudantes dos países objecto do estudo.

Duas dimensões principais foram seleccionadas para este estudo: a primeira referese ao contexto social, económico e político e a segunda considera a configuração do Serviço Social em cada país. A primeira dimensão integra duas sub-dimensões: uma centrada em questões globais relacionadas com factores socioeconómicos e políticos, tais como população e localização, o rendimento e a taxa de pobreza, o tipo de sistema político, especialmente focando no tipo de organização administrativa incluindo os valores em presença. E a outra centrada no modo como o sistema de bem-estar social contribui para a realização do primeiro pilar (pensões contributivas e suplementos), e do segundo pilar (sistema não contributivo das pensões e complementos), e a ligação com serviços existentes, as modalidades de acesso e despesas do país em áreas sociais.

A segunda dimensão refere-se ao Serviço Social e também integra duas subdimensões de análise: um enfoque sobre o Serviço Social como um campo de conhecimento e de acção específico, com referência a seu significado e as teorias que utiliza e sua posição social nas ciências humanas, as questões que abrange o tipo de formação, a duração e a integração nas universidades, a existência de centros de investigação, bem como a produção científica e académica, de periódicos e obras de referência. E outra centrada no Serviço Social como uma profissão, identificando áreas e instituições de intervenção, o estatuto profissional e carreiras na administração pública e em outras organizações que protegem os interesses dos trabalhadores sociais e as relações com outras profissões. 
Analisamos as semelhanças e diferenças do Serviço Social e da profissão de assistente social em relação ao sistema de bem-estar social de cada país e sua evolução. A grelha de análise permitiu identificar certos padrões de evolução do Serviço Social em relação ao sistema de bem-estar social. O primeiro padrão corresponde ao surgimento das primeiras escolas a partir dos anos trinta aos meados dos anos setenta - denominado de "Serviço Social e desenvolvimento do bem-estar", o segundo teve lugar a partir do final dos anos setenta até a década de noventa - denominado de "Serviço Social e consolidação do bem-estar" e, finalmente, nestes últimos 15 anos, a partir da década de noventa, até agora, denominado "Serviço Social e reflexividade do bem-estar".

\section{O serviço social e o desenvolvimento, consolidação e reflexividade do sistema de bem-estar em Portugal, na Espanha e na Alemanha: semelhanças e diferenças}

Os países analisados neste estudo estão localizados na Europa e pertencem à União Europeia. Alemanha (ocidental e oriental) tem uma população de perto de 82 milhões de pessoas, a Espanha tem uma população de 41 milhões e Portugal tem 10,5 milhões de habitantes. O rácio actual da pobreza na Alemanha e quase 13\% (que tem aumentado nos últimos anos), em Portugal e Espanha é de $20 \%$ e nestes dois países, $15 \%$ das pessoas vivem em extrema pobreza, embora este número tenha diminuído nos últimos anos. Hoje, esses países têm um sistema político democrático baseado nos direitos humanos e estão comprometidos com a agenda social (Comissão Europeia, 2000, 2001) para melhorar a qualidade de vida e promover a inclusão social.

\section{Serviço social e desenvolvimento do bem-estar}

O desenvolvimento do Serviço Social relacionado com o sistema de bem-estar situa-se entre os anos trinta e setenta do século 20. Durante este período, Portugal (1933-1975), Espanha (1938-1976), Alemanha (1933-1946) integravam projectos políticos ditatoriais. Durante este período, não houve quaisquer direitos individuais, mas houve certo paternalismo consubstanciado através da filosofia da criação de um ser humano superior e da doutrina religiosa (católica ou não), associada à ideia de Deus, Pátria e Família tanto em Portugal e Espanha. 
Na Alemanha, no rescaldo da Segunda Guerra Mundial, as principais alterações ocorreram em termos de espaço territorial e os sistemas políticos, económicos e sociais. A Alemanha foi dividida em dois países: Alemanha Oriental e Ocidental. O primeiro "adoptou" o regime político associado ao socialismo e valores colectivos e, no segundo, fundou-se um sistema económico liberal e um sistema político multipartidário, dominado pelo Partido Democrata Cristão (CDU) desde 1949 até 1990 (data da reunificação). Este sistema seguiu os princípios democráticos e valores baseados nos direitos humanos (civis, políticos e sociais) e da solidariedade.

Apesar de os valores serem diferentes, estes países (Alemanha Ocidental, Portugal e Espanha), assumiram um sistema semelhante de bem-estar, com base na protecção corporativa de associados aos seguros sociais. Na Alemanha (1961), foi aprovada uma lei para proteger alguns dos grupos mais vulneráveis, como os deficientes e garantir um mínimo de dignidade para cada pessoa. Em Portugal, a protecção foi consubstanciada pelos fundos de previdência (Caixas de Previdência - Lei 1.884 de 1935), dirigida ao comércio, indústria e os trabalhadores dos serviços e funcionários públicos.

Na Espanha, as primeiras formas de segurança social surgiram na década de sessenta (JAUREGI, 2004). Estas medidas foram baseadas no princípio da subsidiariedade. A protecção foi uma responsabilidade assumida por indivíduos que trabalham e os empregadores, a responsabilidade de suporte social, associada a bens e serviços, que foram essenciais para manter o bem-estar e por organizações da sociedade civil. Durante esse período, essas organizações estavam associadas à religião católica e / ou associado à ideologia do regime político (Portugal e Espanha) (JAUREGI, 2004; SOUSA; FIGUEIREDO, 2004). Na Alemanha, havia instituições organizações religiosas vocacionadas para aqueles que não se beneficiavam de seguro social (MEYER, 2004). Para além da sua forma e tipo de protecção social essas organizações materializaram uma concepção paternalista e caritativa da assistência social, dirigido de preferência a indivíduos e famílias considerados "pobres" e/ ou com comportamentos inadequados em relação às normas da classe burguesa. As respostas dadas durante este período foram principalmente a institucionalização e/ ou visitas domiciliares centrada no grupo familiar e das crianças.

Nestes países a institucionalização do Serviço Social está associada ao surgimento das primeiras escolas de Serviço Social. Estas foram instituídas em 1908 na Alemanha, em 
1932 na Espanha e em 1935 em Portugal. A sua criação está associada ao projecto nacionalista e os valores religiosos: "fazer o bem e moralizar os pobres" (MARQUES; MOURO 2004). Durante a guerra civil espanhola e da Segunda Guerra Mundial na Alemanha, a formação em Serviço Social deixou de ser desenvolvida.

Na Alemanha e na Espanha, a formação em Serviço Social teve maior ênfase, desde 1950 e 1960 (FRIESENBABN; EBLERT, 2004; TELLO, 2004) associada, no primeiro caso, a uma linha de pedagogia social e, no segundo caso, ao movimento feminino franquista. Nos três países estudados a base teórica da profissão era a doutrina social da Igreja e a educação social associada ao trabalho de caso. Nas décadas seguintes, outras formas de intervenção foram aprovadas, associadas à intervenção com grupo e trabalho comunitário.

Durante este período (1930-1970), a profissão desempenhou um papel menor em relação a outras profissões sociais - pois era uma formação intermédia e não superior, desenvolvida principalmente por escolas técnicas ou especializadas. A duração da formação era de 2 e 3 anos, era organizada com uma componente teórica e uma componente prática. Em 1969, na Alemanha, a formação foi integrada em faculdades de ciências sociais aplicadas de carácter pedagógico e incorporada nas universidades. 0 Serviço Social passou a ser chamado de "Sozialpädagogie" (Tello, 2004), e em Portugal e Espanha Serviço Social. Neste período, em Portugal, as escolas aumentaram os anos de formação para 3-4 anos.

Nesta fase do desenvolvimento do bem-estar social, o assistente social era um "modelo", a "mãe universal" e sua acção era principalmente de caridade, de voluntariado e realizado pelas mulheres (GARNIER, 1999). Em países como Portugal e Espanha, esta formação promoveu a emancipação das mulheres, que pertenciam a uma classe social elevada. A acção do Serviço Social reflecte as políticas sociais em vigor na época, concentravam-se principalmente sobre os pobres, viciosos, "indivíduos", mendigos, prostitutas e alcoólatras.

A finalidade da acção do Serviço Social era modificar o comportamento individual e corrigir as falhas na socialização, atribuindo ao Serviço Social um papel reparador, sobretudo em Portugal e Espanha, essa função era igualmente repressiva. A actividade do Serviço Social estava também associada a aspectos burocráticos, realizada em 
organizações de caridade, organizações estatais e privadas, de carácter religioso, associada a uma acção voluntária mal paga e sem carreira profissional.

\section{Serviço social e consolidação do bem-estar}

A fase de consolidação do Serviço Social e do bem-estar está situada entre os anos setenta e noventa do século 20. Nesse período, países como Portugal (1974) e Espanha (1976) e a Alemanha ocidental assumiram um sistema democrático associado aos direitos humanos. No entanto, esses valores estavam ligados à autonomia colectiva (grupo familiar) ao invés de autonomia individual.

Portugal adoptou uma democracia parlamentar e uma administração estatal centralizada e Espanha adoptou uma democracia parlamentar monárquica e uma administração pública descentralizada. Espanha tem 17 regiões com poder legislativo e executivo. Actualmente a Alemanha é um estado parlamentar federal, representado por um chanceler e o poder é tanto centralizado (poder central) como descentralizado (poder regional). Em 1990 estes países (Alemanha ocidental e oriental) foram objecto de uma revolução política que levou à reunificação e a um processo de integração de duas culturas muito diferentes (leste e oeste).

O modelo de bem-estar perseguido durante este período é baseado nos direitos universais com acesso a bens como saúde, educação, justiça, habitação, trabalho e protecção social, especialmente em Portugal e Espanha. O Estado assumiu a responsabilidade pelo bem-estar social, em articulação com outros sistemas: o mercado, sociedade civil e famílias (HESPANHA et al., 2000). No entanto, em Portugal existem algumas leis que regem o direito à saúde, educação, justiça e protecção social como direito universal e outras leis que estão centradas em áreas específicas como o grupo do idoso, famílias, crianças. Há uma multiplicidade de leis e regulamentos, programas e projectos (SOUSA; FIGUEIREDO, 2004). A administração é centralizada e existe uma fraca coordenação dos recursos sociais, o que resulta em desigualdades em termos de oportunidades de acesso.

Na Espanha, há uma diversidade de medidas legislativas para o mesmo problema, dependendo da região - este é o caso da protecção social (TELLO, 2004). Na Alemanha, existem vários tipos de seguros, como seguros de saúde e protecção social. As acções do 
Estado são reguladoras e não executoras. Neste último caso as acções são orientadas para indivíduos e famílias sem nenhum tipo de protecção. Os municípios são responsáveis pela materialização dessas leis, em articulação com organizações sem fins lucrativos que realizam intervenção e são financiados pelo Estado (MEYER, 2004). Neste período a assistência social está focada em alguns grupos que estão relacionadas com a pobreza e a exclusão social. Estes são entendidos como fenómenos interactivos e multidimensionais, cujas causas não são apenas individuais, mas também estruturais e sociais.

O Serviço Social foi objecto de mudanças substanciais durante este tempo, especialmente em Portugal e Espanha. A profissão de assistente social foi denominada em Portugal de "assistente social" ou "técnico social", na Espanha de "trabalhador social" e na Alemanha "pedagogo social". Na Espanha, a duração da formação passou a ser de três anos, em Portugal de quatro anos e na Alemanha três anos, mas não era obrigatório integrar a formação nas universidades.

A partir deste período, o Serviço Social foi permeado por ideias e teorias associadas ao colectivismo e ao marxismo. Essas teorias defendem que a mudança social e o desenvolvimento centram-se na estrutura da sociedade. Essa mudança requer meios para expandir a consciência de grupos e indivíduos que estão sujeitos a qualquer forma de opressão e discriminação. Um dos antecessores mais importante desta metodologia foi o método de Paulo Freire e de outros autores de Serviço Social da América latina como Faleiros, Paulo Netto entre outros.

Em Portugal, além desta perspectiva teórica, as ciências humanas e sociais foram institucionalizadas e esse passo permitiu o surgimento de profissões relacionadas com o Serviço Social como a sociologia, psicologia, antropologia, entre outros. Esta diversidade do conhecimento teórico possibilitou compreender as questões sociais, consideradas como fenómenos multidimensionais e desenvolver novos métodos de intervenção (FRIESENBABN; EBLERT, 2004; MARQUES; MOURO, 2004; TELLO, 2004), por exemplo, o método integrado (concepção, planeamento, intervenção e avaliação) e metodologias alternativas colocadas em prática simultaneamente com outros métodos existentes e já utilizadas pelo Serviço Social.

Durante este período, a profissão começou a adquirir um estatuto diferente em relação ao período anterior associado ao fenómeno da pobreza, deficiência, habitação e 
desenvolvimento social, sobretudo em Portugal e na área da saúde, habitação, escolas, crianças e outros serviços sociais na Alemanha, e na gestão de serviços sociais na Espanha. O assistente social tornou-se um técnico especializado na área de inclusão, integração social e promoção dos direitos subjectivos dos indivíduos e grupos com necessidades específicas.

A partir do final dos anos sessenta em diante, a profissão que era maioritariamente dirigida ao público feminino, integrou os primeiros homens. É também durante este período que se inicia o "trabalho" colectivo integrando, o Serviço Social, equipes multiprofissionais e multidisciplinares e passou a estar integrada nas orientações da política social do Estado. Esta nova forma de concepção de formação e acção permitiram o surgimento de associações profissionais, especialmente em Portugal, onde este processo começou em 1976 e terminou em 1989 com a criação da licenciatura e programas de mestrado e de doutoramento.

\section{Serviço social e reflexividade do bem-estar}

Podemos situar o período de reflexividade do Serviço Social relacionado com o sistema de bem-estar entre a década de noventa, até a actualidade. O bem-estar social desses países tem sido objecto de especialização e centra-se em determinados grupos, actuando sob o princípio da discriminação positiva, a favor de famílias monoparentais, gays e lésbicas, os imigrantes, entre outros, intensificando tanto a responsabilidade individual como a familiar para a proteç̧ão social. Durante este período, o Estado atribui a responsabilidade da protecção social cada vez mais para a sociedade civil, família e para o mercado (ANDREOTTI et al., 2001) fazendo frequentes cortes no orçamento.

A maioria dos apoios sociais, especialmente aqueles relacionados com os cuidados é prestada pelas organizações sem fins lucrativos. No que diz respeito às pensões e complementos, estes são da responsabilidade do Estado, sobretudo na Espanha e Portugal (JAUREGI, 2004; SOUSA; FIGUEIREDO, 2004). Na Alemanha, esta responsabilidade é atribuída a outras entidades que administram os seguros a nível social (pensões), saúde e seguros de dependência (EVERT, 2001; MEYER, 2004). No entanto, enquanto na Espanha e Alemanha o apoio social está sob a responsabilidade dos governos regionais (saúde) e municípios (apoio social), em Portugal, o poder 
administrativo é centralizado e os suportes sociais são geridos pelo sistema de segurança social, juntamente com organizações sem fins lucrativos.

Durante este período, nestes países, o Serviço Social sofreu mudanças significativas. No nível da formação, em Portugal e Espanha, foram criados cursos em Institutos e em Universidades, tanto privadas como estatais. Na Alemanha, a reunificação permitiu o aumento do número de escolas, mas este ainda está abaixo de outros cursos universitários. Nestes países, o Serviço Social é considerado como um campo multidisciplinar do conhecimento, apoiado pela sociologia, psicologia, pedagogia, direito, economia e outras ciências. O conhecimento é dominado por uma perspectiva ecológica e sistémica, bem como abordagens dinâmicas e interactivas que incluem a análise e intervenção simultaneamente a nível micro, meso e macro (PAYNE, 1998), associada ao construtivismo, mas também para o estruturalismo.

Foi também introduzida a formação de pós-graduação e especializações em determinadas áreas a fim de abordar a multiplicidade de problemas, a evolução dos conhecimentos científicos e da intervenção do Estado, especialmente em Portugal e Espanha. Apesar destas inovações, nestes países, o Serviço Social é ainda um trabalho feminino integrado em certas medidas programáticas associadas à acção política e consubstanciado em programas e projectos neoliberal. Esta acção revela uma tendência para se especializar nas áreas da infância, família, grupos discriminados e oprimidos, vítimas e agressores e outras situações-problema, tais como o rendimento mínimo, abuso de álcool e drogas. O Serviço Social é predominantemente desenvolvido em instituições públicas, privadas e organizações sem fins lucrativos e a sua acção integra equipes multidisciplinares, através de redes de parceria (principalmente em Portugal e Espanha).

\section{Para concluir}

Actualmente, o sistema de bem-estar responde a uma multiplicidade de problemas e o Serviço Social tem um papel fundamental nessa tarefa. O Serviço Social utiliza o seu conhecimento para definir as estratégias de acção (FALEIROS, 1997; FOOK, 2003), para actuar face aos desafios colocados pelas sociedades de hoje. A acção social tem lugar em organizações sem fins lucrativos, bem como organismos públicos, com uma relativa autonomia (ESCOBEDO; FERNANDEZ; MORENO, 2002). A sua acção é influenciada pela 
forma como cada país é capaz de administrar e coordenar as suas políticas de bem-estar e tem uma grande importância na promoção da inclusão social e o desenvolvimento da sociedade.

Com base nesta reflexão, podemos concluir que o Serviço Social e o bem-estar, como produto do processo de modernização social, visam o desenvolvimento e consolidação dos vários sistemas da sociedade tendo em conta o modo como interagem e se comunicam, permitindo a existência de certos sub-padrões de bem-estar social e de trabalho nos países estudados - sendo possível identificar algumas diferenças e semelhanças.

As diferenças estão principalmente relacionadas com os princípios, valores e culturas das sociedades estudadas, que determinam sub-padrões de bem-estar - alguns são mais centralizados (Portugal) e outros descentralizados (Espanha e Alemanha) - e subpadrões de Serviço Social - alguns são orientados para uma formação geral e específica com o reconhecimento dos graus académicos de licenciado, mestre e doutor em Portugal e menos reconhecidas em outros países (Espanha e Alemanha).

Dentro dessas sub-especificidades, existem algumas semelhanças no que diz respeito ao Serviço Social: é uma área das ciências sociais e humanas, que utiliza os conhecimentos de sociologia, psicologia, psiquiatria, política social e pedagogia. Este último é mais acentuado na Alemanha do que nos outros países estudados. Os seus princípios e valores estão associados aos direitos humanos, democracia, justiça social, humanismo e autodeterminação (INTERNATIONAL FEDERATION OF SOCIAL WORKERS, 2004) mais do que os valores morais da doutrina social da Igreja e da filosofia da "raça superior", em que o serviço social começou a se desenvolver. No entanto, ainda hoje o Serviço Social é criticado por estar associado ao poder das instituições mais do que às necessidades dos clientes e a sua acção é também criticada por estar associada a um certo pragmatismo "imediatista" (NEGREIROS, 1995), significa resolver os problemas rapidamente, sem reflectir sobre as suas causas e consequências.

O Serviço Social é considerado como uma prática social ou uma ciência prática, que se desenvolve na sociedade, com autonomia de critérios e, simultaneamente, com uma responsabilidade social. Utiliza teorias e metodologias de intervenção nos processos de pobreza, exclusão, opressão, discriminação, violência, violação dos direitos humanos e 
promove a capacitação e cidadania dos indivíduos, comunidades e sociedades (INTERNATIONAL FEDERATION OF SOCIAL WORKERS, 2000). Seu principal objectivo é promover o desenvolvimento social e o bem-estar e para incluir e reeducar as pessoas excluídas, de acordo com os princípios da justiça social, da autodeterminação e da cidadania.

A sua acção realizada no âmbito do sistema de bem-estar é centrada em sectores específicos, como a área de segurança social, saúde, justiça, educação, habitação e outros. As instituições sociais, onde o Serviço Social desenvolve actividades nas áreas de família, crianças, jovens, deficientes, idosos, refugiados, imigrantes e outros grupos. A intervenção dos assistentes sociais com estes grupos é orientada para a protecção e empowerment - em termos sociais e/ ou psicossocial ou de desenvolvimento pedagógico - e trabalham em conjunto com outros profissionais em equipes multidisciplinares. As intervenções podem centrar-se em processos de informação, de apoio, de acompanhamento, de orientação, de administração de serviços, de elaboração de programas e projectos, de mobilização de recursos e concepção, de planeamento e avaliação do processo de intervenção.

Em suma, o Serviço Social requer uma consolidação académica e profissional com base na definição internacional do Serviço Social. Os assistentes sociais têm um compromisso tanto com o contexto social e político, os valores da sociedade, as teorias e os processos de intervenção nos problemas sociais, como com a produção de conhecimento sobre a profissão e sobre as questões sociais (PAYNE, 1995). Numa sociedade global, o Serviço Social constrói o conhecimento com base na reflexão sobre a profissão e os problemas existentes em cada sociedade, bem como sobre o modo como as organizações da sociedade respondem ou não respondem aos mesmos (PAYNE, 1998).

A fim de ser capaz de atingir os novos conhecimentos, os assistentes sociais exigem um ensino teórico e prático que lhes permite construir saberes analíticos, operacionais, relacionais e comunicativos. Este saber é regulamentado por padrões teóricos e deontológicos de associação entre teoria e prática, com uma continuada e reflexiva autoconfrontação, permitindo, por um lado, construir um conhecimento específico e coerente e, por outro lado, melhorar as práticas existentes. Desta forma, serão capazes de 
compartilhar o mesmo reconhecimento social e de outros profissionais de ciências humanas e contribuir para a construção de uma sociedade mais justa.

\section{Referências}

ANDREOTTI, A. et al. Does a southern european model exist? Journal of European Area Studies, London, v. 9, n. 1, 2001.

BERGER, P.; LUCKMANN, T. A construção social da realidade. Lisboa: Dinalivro, 1987.

COMISSÃO EUROPEIA Agenda de Lisboa. Luxemburgo: Serviço das Publicações Oficiais das Comunidades Europeias, 2000.

COMISSÃO EUROPEIA. Agenda social Europeia Aprovada pelo Conselho Europeu de Nice de 7,8 e 9 de Dezembro de 2000. Luxemburgo, Serviço das Publicações Oficiais das Comunidades Europeias, 2001

COUSINS, M. European welfare states, comparative perspectives. London: Sage Publications, 2005.

ESCOBEDO, A.; FERNANDEZ, E.; MORENO, D. Surveying demand supply and use of care WP 4, in care work in Europe, current understandings and future directions. Barcelona: Thomas Coram Research Unit, Institute of Education, University of London, Ciren Foundation, 2002.

EVERT, A. El nuevo programa de seguro para cuidados de longa duración en Alemania, in observatorio de personas mayores, vejez y protección social a la dependencia en Europa. Madrid: Artegraf, 2001

FALEIROS, V. P. Estratégias em serviço social. São Paulo: Cortez, 1997.

FLORA, P.; HEIDENHEIMER, A. J. The development of welfare states in europe and américa. London: Transaction Publishers, 1995

FOOK, J. Social work, critical theory and practice. London: Sage, 2003.

FREIRE, P. A pedagogia do oprimido, Porto: Afrontamento, 1975.

FRIESENBABN, G. J.; EBLERT, G. Germany. In: CAMPANINI, A.; FROST, E. European social work, commonalities and differences. Roma: Caracci, 2004. p. 85-94.

GARNIER, J. F. Assistante social, pour la redefinition d'un Metier. Paris: L'Harmattan, 1999.

HABERMAS, J. Teoria de la acción comunicativa I - Racionalidad de la acción y racionalización social and Teoria de la acción comunicativa II - Crítica de la razón funcionalista. Madrid: Taurus, 1987. 
HESPANHA, P. et al. Entre o estado e o mercado, as fragilidades das instituições de proteç̧ão social em Portugal. Coimbra: Quarteto, 2000.

INTERNATIONAL FEDERATION OF SOCIAL WORKERS -IFSW. Definition of Social Work. 2000. Disponível em: <http://www.ifsw.org/en/p38000208.html>. Acesso em: 5 maio 2010.

INTERNATIONAL FEDERATION OF SOCIAL WORKERS -IFSW. The ethics of social work, principles and standards. 2004. Disponível em:

<http://www.ifsw.org/en/p38000398.html>. Acesso em: 5 maio 2010.

JAUREGI, A. L. National background report for spain, in services for supporting family careers of elderly people in Europe: characteristics, coverage and usage. Hamburg: Eurofamcare, 2004.

KANTOWICZ, E. Dilemmas in comparative research of education for social work in Europe, European. Journal of Social Work, London, v. 8, n. 3, p. 297-309, 2005.

MARQUES, E.; MOURO, H. Portugal. In: CAMPANINI, A.; FROST, E. European social work, commonalities and differences. Roma: Caracci, 2004. p. 182-188.

MEYER, M. National background report for Germany, in services for supporting family careers of elderly people in europe: characteristics, coverage and usage. Hamburg: Eurofamcare, 2004.

MOZZICAFREDDO, J. Estado providência e cidadania em Portugal, Oeiras: Celta 2000.

NEGREIROS, A. G. As representações sociais da profissão de serviço social. Lisboa: Lisboa: Instituto Superior de Serviço Social de Lisboa, 1995.

PAYNE, M. Teorias contemporáneas del trabajo social. Barcelona: Paidós Ibérica, 1995.

PAYNE. Social work theories and reflexive practice. In: ADAMS, R.; DOMINELLI, L.; PAYNE, M. Social work-themes, issues and critical debates. Londres: Macmillan, 1998.

SOUSA, L.; FIGUEIREDO, D. National background report for Portugal, in services for supporting family careers of elderly people in Europe: characteristics, coverage and usage. Hamburg: Eurofamcare, 2004.

TELLO, T. B. Spain. In: CAMPANINI, A.; FROST, E.European social work, commonalities and differences. Roma: Caracci, 2004. p. 95-101.

VEENKAMP, R. European constructivism. Netherlands: University of Inholland, 2006. Paper.

Recebido em: 02/02/2011

Aprovado em: 10/03/2011 